\title{
Effects of photoperiod and light spectra on growth and pigment composition of the green macroalga Codium tomentosum
}

\author{
Rúben Marques ${ }^{1} \cdot$ Sónia Cruz ${ }^{1}$. Ricardo Calado ${ }^{1} \cdot$ Ana Lillebø $^{1} \cdot$ Helena Abreu $^{2} \cdot$ Rui Pereira $^{2,3} \cdot$ Bárbara Pitarma $^{2}$. \\ Jorge Marques da Silva ${ }^{4} \cdot$ Paulo Cartaxana ${ }^{1}$ (D)
}

Received: 9 June 2020 / Revised and accepted: 30 September 2020 / Published online: 24 October 2020

(C) The Author(s) 2020

\begin{abstract}
Codium tomentosum is a marine green macroalga with multiple value-added applications that is being successfully used as an extractive species in sustainable integrated multi-trophic aquaculture systems. Nonetheless, growth conditions of this species at an early development phase still require optimization. The present study addresses, under controlled laboratory conditions, the effects of photoperiod (long vs. short-day) and light spectra (white, blue, and red light) on growth and pigment composition of C. tomentosum. Relative growth rate was approximately $2 \times$ higher under long-day photoperiod (average of 39.2 and $20.1 \%$ week $^{-1}$ for long and short-day, respectively). Concentrations per dry weight of major pigments such as chlorophyll $a$ (Chl $a$ ) and siphonoxanthin (Siph) were significantly higher under long-day photoperiod. Relative growth rates were higher under red light, intermediate under white light, and lower under blue light. These last results were rather surprising, as Siph-Chla/Chl $b$ light harvesting complexes of Codium have increased absorption in the blue-green region of the light spectra. Changes in carbon allocation patterns caused by the spectral composition of light and overgrowth of green microalgae in blue light cultures could explain the differences recorded for relative growth rate. Long-day photoperiod and light sources with preferential emission at the red region of the light spectra were identified as optimal for growth of $C$. tomentosum at early development stages. These lighting conditions can reduce the time required to reach the necessary biomass before transfer to grow-out systems. Overall, these findings can shorten production time, increase macroalgal productivity, and enhance aquaculture revenues.
\end{abstract}

Keywords Chlorophyta $\cdot$ Aquaculture $\cdot$ Growth rate $\cdot$ Irradiance $\cdot$ Nursery $\cdot$ Photosynthesis $\cdot$ Productivity

\section{Introduction}

Environmental concerns related to traditional fish aquaculture practices include oxygen depletion, eutrophication, and algal blooms, resulting from nutrient-enriched effluent discharges to adjacent aquatic environments (Pillay 2004). Integrated

Paulo Cartaxana

pcartaxana@ua.pt

1 ECOMARE, CESAM, Department of Biology, University of Aveiro, Campus Universitário de Santiago,

3810-193 Aveiro, Portugal

2 ALGAplus Produção e Comercialização de Algas e seus Derivados Lda., 3830-352 Ilhavo, Portugal

3 Present address: A4F Algae for Future, Estrada do Paço do Lumiar, Campus do Lumiar, Edif. E, R/C, 1649-038 Lisbon, Portugal

4 BioISI and Department of Plant Biology, Faculty of Sciences, University of Lisbon, Campo Grande, 1749-016 Lisbon, Portugal multi-trophic aquaculture (IMTA) approaches have emerged, as these include extractive species from different trophic levels to uptake available nutrients in effluent waters. This practice is perceived as more environmentally friendly and economically sustainable (Granada et al. 2016). The inclusion of certain macroalgal species in IMTA systems allows the reduction of costs of lowering inorganic nutrient loads in aquaculture effluents and the production of an additional value-added product (Troell et al. 2003). Macroalgae are important natural resources explored for a variety of purposes, mainly as food and feed, but also as biofuels, biostimulants, and cosmetics (Samaraweera et al. 2011; Abreu et al. 2014; Santos et al. 2015).

Codium is a genus of siphonous green macroalgae (Chlorophyta) that is either farmed or foraged from the wild. Codium species are known to be an important source of sulfated polysaccharides (Wang et al. 2014) and other compounds with multiple bioactive properties, such as antioxidant, antiviral, anticoagulant, antiangiogenic, and antitumoral 
activities (Matsubara et al. 2000; Ohta et al. 2009; Ganesan et al. 2010, 2011; Rey et al. 2020). Recently, farmed biomass of the native Atlantic species Codium tomentosum was shown to be a valuable source of important phytochemicals, such as stigmasterol and $\alpha$-tocopherol (Santos et al. 2015), also being rich in polyunsaturated fatty acids with nutritional and health benefits (Costa et al. 2015). Extracts of $C$. tomentosum are already being successfully used as a moisturizing agent in the cosmeceutical industry (Wang et al. 2015; Pereira 2018). Codium is also ranked amongst one of the most popular edible macroalgae and is listed as a delicacy in gourmet cuisine (Radulovich et al. 2015; Pérez-Lloréns et al. 2018).

The pigment composition of siphonous green macroalgae is characterized by the presence of the keto-carotenoid siphonaxanthin and its ester siphonaxanthin dodecenoate (siphonein) as the main light-harvesting carotenoids (Anderson 1983; Wang et al. 2013). Light-harvesting complexes of siphonous green alga are considered an evolutionary relic of some Chlorophyta, in which the presence of siphonoxanthin and chlorophyll $b$ allows an increased absorption in the green and blue-green light region (Anderson 1983; Akimoto et al. 2007; Wang et al. 2013). Another peculiarity of siphonous green macroalgae of order Bryopsidales, which includes Codium spp., is the absence of zeaxanthin as a nonphotochemical quencher (Cruz et al. 2015; Christa et al. 2017). Whereas higher plants and most algae rely on a xanthophyll cycle to dissipate excessive absorbed light energy as heat under high irradiance, Bryopsidales macroalgae lack this important photoprotection mechanism (Christa et al. 2017). It is still not clear which are the main mechanisms contributing to the protection of Bryopsidales from excessive light exposure.

Studies addressing optimal growth conditions for Codium species are still scarce. Yang et al. (1997) observed that filamentous thalli of several Codium species grew over a broad range of environmental conditions. Higher growth rates of C. fragile ssp. tomentosoides were obtained with temperatures ranging from 18 to $24^{\circ} \mathrm{C}$ and a long-day photoperiod of $16 \mathrm{~h}$ of light per day (Hanisak 1979). Hwang et al. (2008) observed that optimal light doses for growth of $C$. fragile differed according to culture stage. Variation of the optimum light requirements for the latter species suggests that the different life stages may be sensitive not only to total irradiance but also to spectral composition (Hwang et al. 2008).

The species C. tomentosum is currently produced in a land-based organic certified IMTA system operated by the company ALGAplus (Portugal) using nutrient-rich effluent from earthen ponds employed for the semi-intensive farming of European sea bass and gilthead sea bream. The company has initiated the cultivation of $C$. tomentosum in 2013, having developed proprietary protocols for year-round production of this species, combining an initial hatchery phase under controlled temperature, photoperiod, and light conditions with an outdoor phase where C. tomentosum is grown in free-floating conditions. As the company operates several macroalgae species, the conditions in the hatchery phase are not optimized for C. tomentosum. Thus, in this study, we tested under controlled laboratory conditions the effects of photoperiod (long vs. short-day; LD and SD, respectively) and light spectra (white, blue, and red light; WL, BL, and RL, respectively) on the growth and pigment composition of $C$. tomentosum at an initial growth phase. Optimizing growth conditions at this stage can reduce the time required at an initial development phase, allowing a faster transfer to grow-out systems and reducing farming operational costs. Ultimately, by fine-tuning lighting practices at this early step of production, it may be possible to more rapidly satisfy the current growing demand by the market of Codium biomass.

\section{Materials and methods}

\section{Biological material and culturing conditions}

Domesticated thalli of Codium tomentosum (Stackhouse, 1797) were supplied in February 2019 by the company ALGAplus (variety C2.21.AC.160309). For acclimation purposes, the macroalga was grown for 2 weeks, under a light intensity of $230 \mu \mathrm{mol}$ photons $\mathrm{m}^{-2} \mathrm{~s}^{-1}$, a temperature of $17 \pm 1{ }^{\circ} \mathrm{C}$, and two photoperiods: long-day (16 h light: $8 \mathrm{~h}$ dark) and short-day ( $8 \mathrm{~h}$ light:16 h dark). Illumination was provided by OSRAM Fluora T8 58W/ 77 fluorescent lamps. Each culture was grown in $1 \mathrm{~L}$ of culture medium in 2-L flasks with aeration strong enough to move the thalli around. Irradiance was quantified inside the culture flasks using a US-SQS/L spherical micro quantum sensor connected to a Universal Light Meter ULM-500 (Walz, Germany). Culture media was the same used at the experimental trials conducted by ALGAplus, consisting of autoclaved nutrient-rich seawater supplemented with VSE and germanium dioxide to prevent the growth of unwanted diatoms in experimental cultures.

\section{Photoperiod experiment}

The photoperiod experiment was designed to test the effects of two different photoperiods in the growth of C. tomentosum: long-day (16 h light: $8 \mathrm{~h}$ dark; LD) and short-day $(8 \mathrm{~h}$ light:16 h dark; SD). After the acclimation period described above, the macroalga was monitored over 5 consecutive weeks with 5 replicates per photoperiod. Algal culture maintenance was performed weekly, with glassware and medium being replaced and algal biomass stocking density adjusted to initial density (10-15 apices of $C$. tomentosum of ca. $2 \mathrm{~cm}$ of length per liter of culture). 


\section{Light spectra experiment}

The light spectra experiment was designed to test the effects of three different light spectra in the growth of C. tomentosum: white, red, and blue light (WL, RL, and BL, respectively). The same quantum irradiance of $120 \mu \mathrm{mol}$ photons $\mathrm{m}^{-2} \mathrm{~s}^{-1}$ was used for WL (consisting in the total spectrum of OSRAM Fluora T8 fluorescent lamps), RL (a red Lee Filter allowing the red part of the light spectrum to be transmitted), and BL (a blue Lee Filter allowing the blue part of the light spectrum to be transmitted). Light spectra (Fig. 1) were measured using an OceanOptics spectrometer (Flame model, wavelength range 190-1100 nm). The macroalga was monitored for 5 consecutive weeks at long-day photoperiod ( $16 \mathrm{~h}$ light: $8 \mathrm{~h}$ dark) and at $17 \pm 1{ }^{\circ} \mathrm{C}$. This photoperiod was used due to the higher growth rates observed (see "Results"). Maintenance of algal cultures was performed weekly as described above, with algal biomass density adjusted to the initial density.

\section{Biomass quantification}

Macroalgal biomass was quantified every week. The macroalga was transferred to a Petri dish and excess of growth medium removed with two pieces of paper towel. The fresh biomass was then weighted using a precision scale. Relative growth rate (RGR) was calculated according to the equation $\left[\operatorname{Ln}\left(W_{\mathrm{f}}\right)-\operatorname{Ln}\left(W_{\mathrm{i}}\right)\right] / t \times 100$, where $W_{\mathrm{f}}$ is the final fresh weight and $W_{\mathrm{i}}$ is the initial fresh weight, while $t$ refers to time expressed in weeks.

\section{Chlorophyll fluorescence}

In vivo chlorophyll (Chl) $a$ fluorescence was measured using an Imaging-PAM fluorometer Mini version (Walz, Germany).

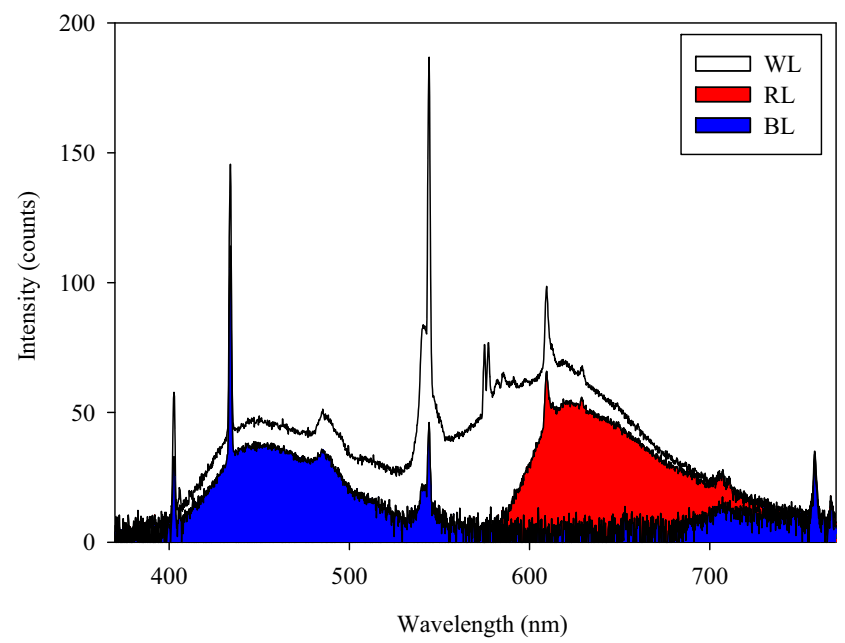

Fig. 1 Emission spectra of growth lights (WL - white light, OSRAM Fluora T8 fluorescent lamps; RL—red light; and BL—blue light). RL and $\mathrm{BL}$ were obtained using wavelength-selective filters over white light
A characterization of photosynthetic activity was performed through steady-state light-response curves (SSLC) measured at the end of each experimental period (week 5). First, the macroalgal samples were dark-acclimated for $15 \mathrm{~min}$ and maximum quantum yield of photosystem (PS) II $\left(F_{\mathrm{v}} / F_{\mathrm{m}}\right)$ was determined by calculating $\left(F_{\mathrm{m}}-F_{\mathrm{o}}\right) / F_{\mathrm{m}}$, where $F_{\mathrm{m}}$ and $F_{\mathrm{o}}$ are the maximum and the minimum fluorescence of the dark-adapted samples, respectively (Murchie and Lawson 2013). Secondly, measurements of the effective PSII quantum yield were obtained at the end of 9 steps of $5 \mathrm{~min}$ of increasing irradiances up to $604 \mu \mathrm{mol}$ photons $\mathrm{m}^{-2} \mathrm{~s}^{-1}$. Measurements were done at constant temperature $\left(17 \pm 1^{\circ} \mathrm{C}\right)$ and at the same time of the day (measurements started $6 \mathrm{~h}$ after the onset of light). Steady-state light-response curves were constructed by calculating, for each level of actinic light, the relative electron transport rate (rETR) at the delivered actinic photon irradiance $(E)$, and the effective quantum yield of PSII $\left(\Delta F / F_{\mathrm{m}}\right)$ as rETR $=E \times\left(F_{\mathrm{m}}{ }^{\prime}-F\right) / F_{\mathrm{m}}{ }^{\prime}$, where $F_{\mathrm{m}}{ }^{\prime}$ and $F$ are the maximum and the steady-state fluorescence of light exposed samples, respectively (Genty et al. 1989). Numerical values of variable Chl fluorescence parameters were extracted from the digital images using the imaging system software (Imaging Win, Heinz Walz GmbH, Germany) by selecting areas of interest. Light curves were characterized by fitting the model of Platt et al. (1980). The estimated parameters were (i) $\alpha$ (initial slope of ETR versus E curve), representing the light utilization coefficient and related to the photosynthetic efficiency at limiting irradiances; (ii) $\mathrm{rETR}_{\max }$ (maximum relative ETR) related to the photosynthetic capacity at saturating irradiances. The model was fitted iteratively using MS Excel Solver. The curve fits obtained were always considered as very good $(r>0.98)$.

\section{Photosynthetic pigments analysis}

At the end of the experimental periods, macroalgal material was flash-frozen in liquid nitrogen and freeze-dried prior to photosynthetic pigment analysis. Pigment quantification by high-performance liquid chromatography (HPLC) followed the $\mathrm{C} 18$ method described by Mendes et al. (2007). For every extraction, the amount of lyophilized sample used followed the ratio of $40 \mathrm{mg}$ per $1 \mathrm{~mL}$ of extraction solution (95\% cold buffered methanol with $2 \%$ ammonium acetate). Samples were ground with a plastic rod and sonicated for $1 \mathrm{~min}$. Samples were then transferred to $-20{ }^{\circ} \mathrm{C}$ for $20 \mathrm{~min}$ in the dark. Extracts were filtered through $0.2 \mu \mathrm{m}$ PTFE membrane filters and immediately injected into a Prominence- $i$ LC 2030C HPLC system (Shimadzu, Japan) with a photodiode array detector. Chromatographic separation was carried out using a Supelcosil C18 column (250 mm length; $4.6 \mathrm{~mm}$ diameter; $5 \mu \mathrm{m}$ particles; Sigma-Aldrich, USA) for reversephase chromatography and a 35 min elution program. The solvent gradient followed Kraay et al. (1992), with an injection volume of $50 \mu \mathrm{L}$ and a flow rate of $0.6 \mathrm{~mL} \mathrm{~min}{ }^{-1}$. 
Pigments were identified from absorbance spectra and retention times and concentrations calculated from the signals in the photodiode array detector in comparison with pure crystalline standards from DHI (Hørsolm, Denmark). The concentration of each pigment was expressed per dry weight $\left(\mu \mathrm{mol} \mathrm{g} \mathrm{dw}{ }^{-1}\right)$.

\section{Statistical analysis}

Significant differences in relative growth rate were tested using a mixed ANOVA (within-subjects factor, time; between-subjects factor, light treatment), after checking for homogeneity of variances (Levene's Test), normality (Shapiro-Wilk's test), and sphericity (Mauchly's test). Multiple comparisons were performed with Tukey's test with significance levels adjusted by the Bonferroni correction. For the fluorescence parameters $\left(F_{\mathrm{v}} / F_{\mathrm{m}}, \alpha\right.$, $\mathrm{rETR}_{\max }$, and $E_{\mathrm{k}}$ ) and pigment concentrations, differences between photoperiods (long- and short-day) were tested for significance using a $t$ test, while those between light spectral treatments (white, red, and blue light) were investigated using one-way ANOVA. The nonparametric Kruskal-Wallis test was used when data violated assumptions of normality or homogeneity of variances. Statistical analysis was done using SPSS Statistics v25.0 for Windows.

\section{Results}

\section{Photoperiod experiment}

The relative growth rate (RGR) of $C$. tomentosum under long-day (16 h light:8 h dark; LD) photoperiod was significantly higher $\left(F_{1,8}=129.8, p<0.001\right)$ than that recorded under short-day ( $8 \mathrm{~h}$ light:16 h dark; SD) conditions (Fig. 2). Multiple comparisons revealed significant differences between light treatments (in all cases $p<0.001$ ) for all time points (weeks). Average RGR observed were $39.2 \pm 3.2$ and $20.1 \pm 1.9 \%$ week $^{-1}$ for LD and SD, respectively. Within each treatment, along the 5-week growth period, C. tomentosum cultures growth rates decreased from week 1 to week 3 , but the RGR values leveled on week 4 and 5 .

Maximum quantum yield $\left(F_{\mathrm{v}} / F_{\mathrm{m}}\right)$ of $C$. tomentosum at week 5 was $0.73 \pm 0.01$ under both LD and SD photoperiods. Light curves were also similar between photoperiods, with relative electron transport rate increasing with irradiance and saturating at light intensities ca. $200 \mu \mathrm{mol}$ photons $\mathrm{m}^{-2} \mathrm{~s}^{-1}$ (Fig. 3). No significant differences were observed between LD and SD treatments for steady-state light-response curves (SSLC) parameters $\alpha(0.90 \pm 0.11$ and $0.80 \pm 0.09$, respectively) and $\mathrm{rETR}_{\max }(26.8 \pm 4.0$

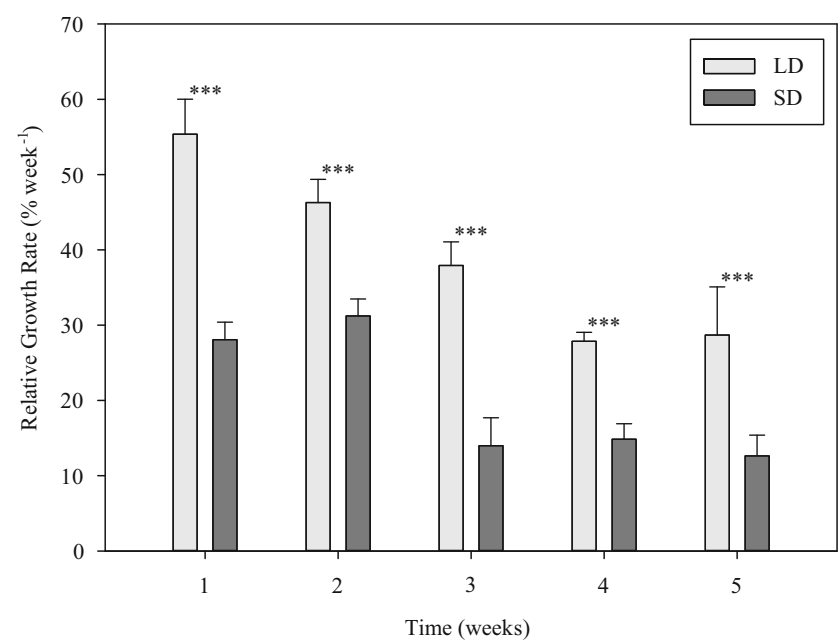

Fig. 2 Relative growth rate of Codium tomentosum (mean $\pm \mathrm{SD}, n=5$ ) along a 5 -week growth period under long-day photoperiod ( $16 \mathrm{~h} \mathrm{light:8 \textrm {h }}$ dark, LD) and short-day photoperiod ( $8 \mathrm{~h}$ light:16 h dark, SD). Differences between light treatments were significant in all cases at $p<0.001$ (triple asterisk)

and $27.0 \pm 1.8$, respectively). However, Chl fluorescence parameters revealed high spatial heterogeneity within the macroalgal thallus. A gradient was observed with higher $F_{o}$ values and lower photosynthetic yields registered at the macroalgal tips, when compared with basal areas of the thallus (Fig. 4).

Pigments identified in C. tomentosum by HPLC included (by elution order) siphonoxanthin (Siph), all-trans-neoxanthin $(t$-Neo), 9'-cis-neoxanthin ( $c$-Neo), violaxanthin (Viola), siphonaxanthin dodecenoate (Siph-do), chlorophyll $b(\mathrm{Chl} b)$, chlorophyll $a$ (Chla), and $\beta, \varepsilon$-carotene ( $\beta \varepsilon$-Car) (Table 1$)$. Average pigment concentrations were higher under LD

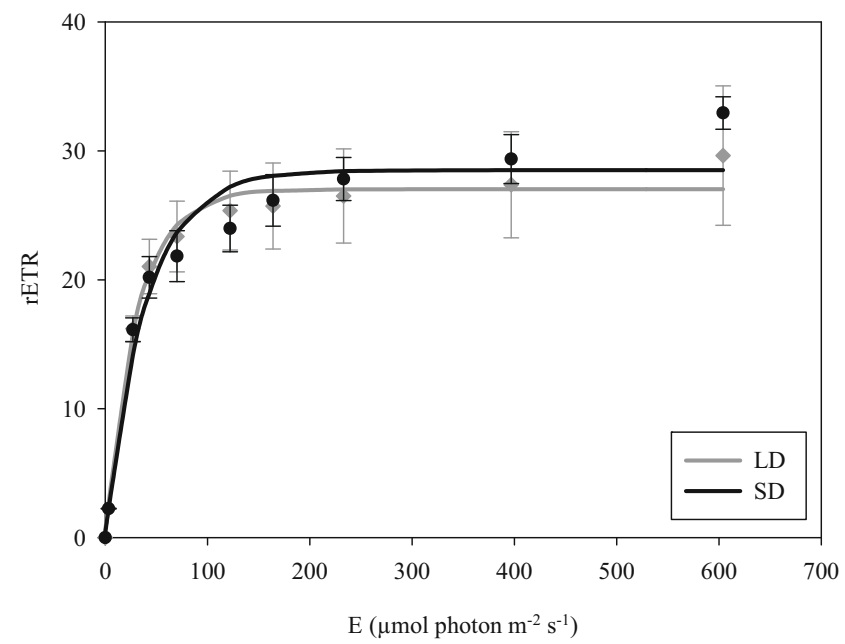

Fig. 3 Steady state light-response curves of relative electron transport rate (rETR) vs. photon irradiance (E) in Codium tomentosum (mean \pm $\mathrm{SD}, n=5$ ) after 5 weeks under long-day photoperiod ( $16 \mathrm{~h}$ light: $8 \mathrm{~h}$ dark, LD) and short-day photoperiod ( $8 \mathrm{~h}$ light:16 h dark, SD). Lines represent curve fits according to the model by Platt et al. (1980) 
Fig. 4 Fluorescence heterogeneity in Codium tomentosum. a Maximum fluorescence $\left(F_{m}\right)$ map measured in 15 min dark-adapted samples of $C$. tomentosum. b Minimal fluorescence $\left(F_{o}\right)$ and maximum photosynthetic yield $\left(F_{v} / F_{m}\right)$ in transect 0-321 represented in a

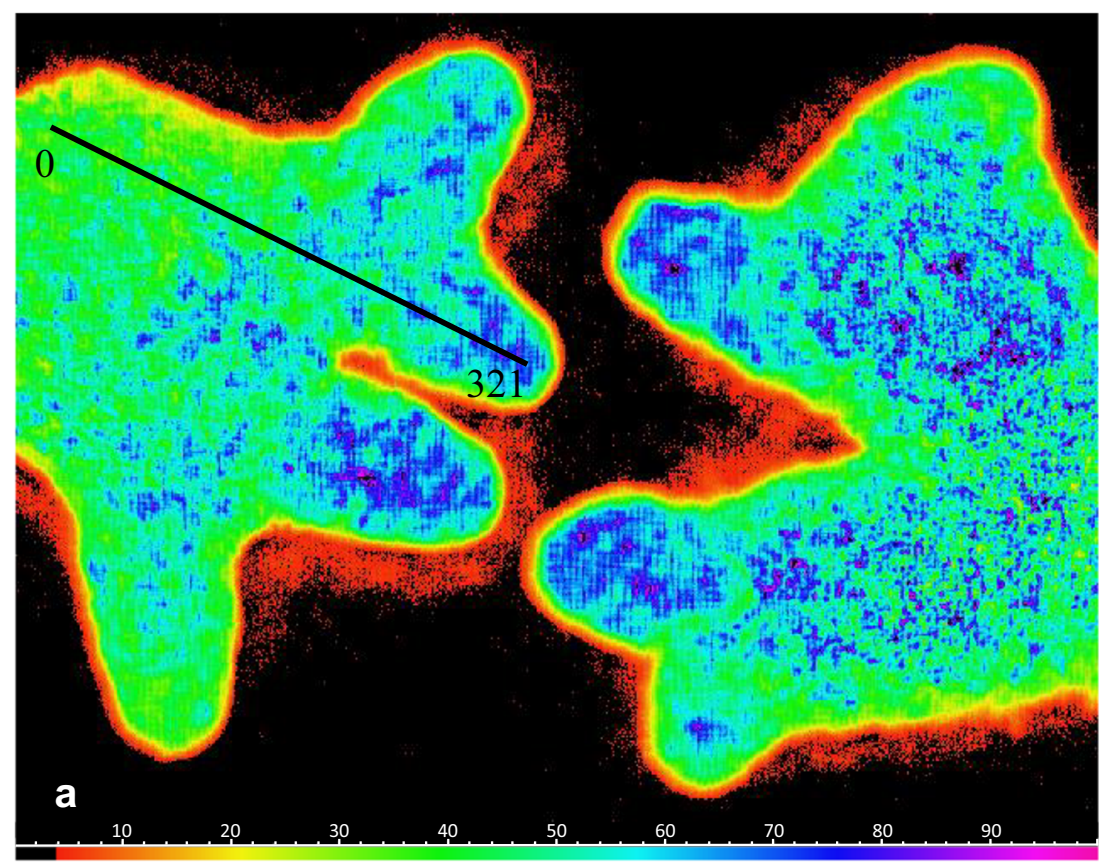

- Fo $-\mathrm{Fv} / \mathrm{Fm}$

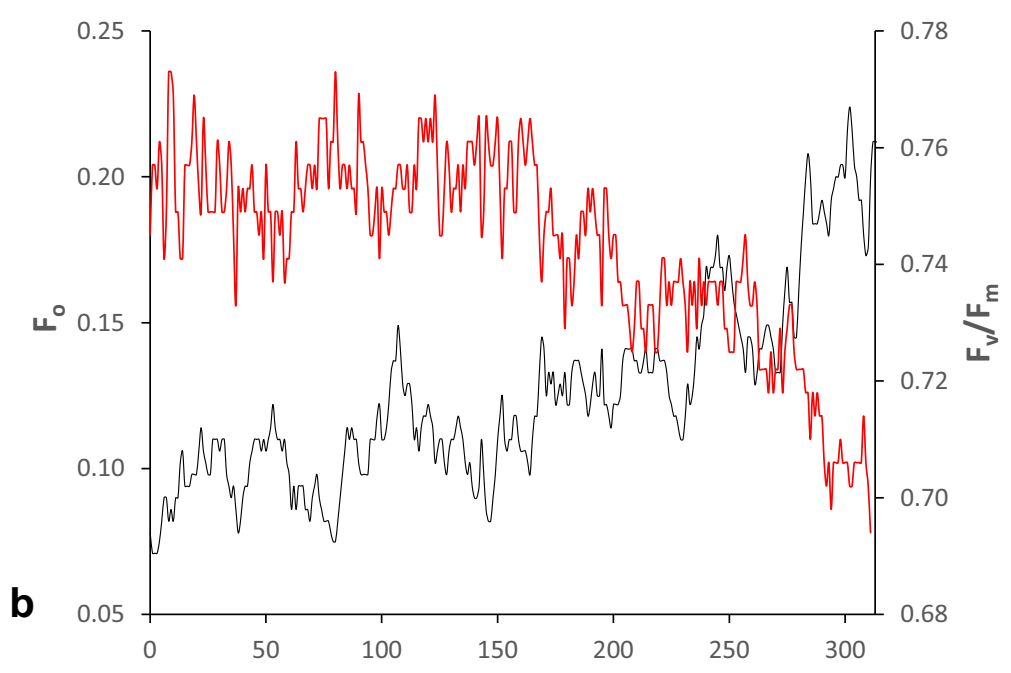

conditions for all the pigments identified (Fig. 5). However, pigment concentrations were only significantly higher $(p<0.05)$ under LD conditions for Siph, $c$-Neo, Viola, and Chl $a$. The remaining pigments ( $t$-Neo, Siph-do, Chlb, and
Table 1 List of photosynthetic pigments identified in Codium tomentosum, with average retention times and absorption $\operatorname{maxima}\left(\lambda_{\max }\right)$

\begin{tabular}{lll}
\hline Pigments & Retention time (min) & $\lambda_{\max }(\mathrm{nm})$ \\
\hline Siphonoxanthin (Siph) & 10.51 & 448 \\
All-trans-neoxanthin $(t$-Neo) & 11.49 & $418,441,471$ \\
$9^{\prime}$-cis-neoxanthin $(c$-Neo) & 12.12 & $413,437,466$ \\
Violaxanthin (Viola) & 13.11 & $417,441,471$ \\
Siphonaxanthin dodecenoate (Siph-do) & 18.67 & 455 \\
Chlorophyll $b(\mathrm{Ch} b)$ & 22.85 & $458,595,645$ \\
Chlorophyll $b(\mathrm{Ch} a)$ & 24.40 & $430,622,667$ \\
$\beta, \varepsilon$-carotene $(\beta \varepsilon$-Car) & 28.53 & 447,475 \\
\hline
\end{tabular}




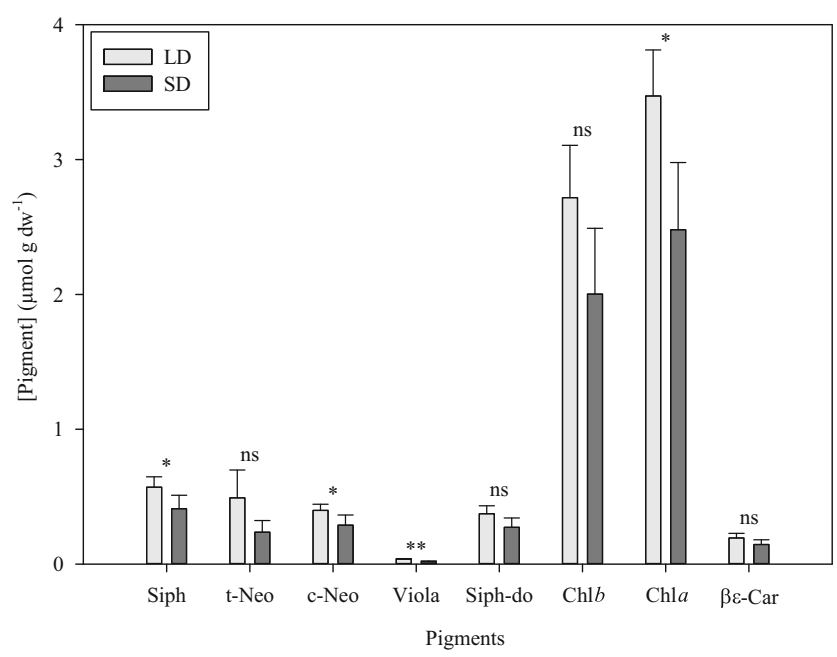

Fig. 5 Pigment content in Codium tomentosum (mean $\pm \mathrm{SD}, n=4$ ) at week 5 under long-day photoperiod (16 h light:8 h dark, LD) and shortday photoperiod ( $8 \mathrm{~h}$ light:16 h dark, SD). Differences between light treatments were nonsignificant (ns), significant at $p<0.05$ (single asterisk), or significant at $p<0.01$ (double asterisk)

$\beta \varepsilon$-car) showed no significant difference between photoperiods.

\section{Light spectra experiment}

There was a significant effect of light spectral treatment $\left(F_{2,12}=33.8, p<0.001\right)$ on the RGR of $C$. tomentosum (Fig. 6). RGR was significantly higher under RL, intermediate in WL, and lower in BL (in all cases $p<0.05$ ). Average RGR observed were $36.7 \pm 2.7,31.5 \pm 1.4$, and $21.8 \pm 3.3 \%$ week $^{-1}$ for RL, WL, and BL, respectively. Along the 5-week growth period, $C$. tomentosum growth rates were consistently lower

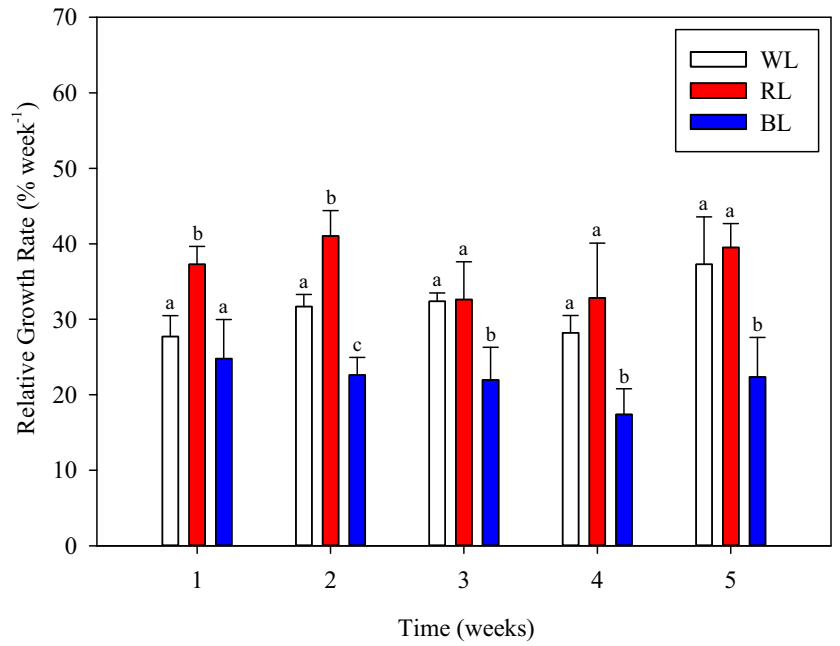

Fig. 6 Relative growth rate of Codium tomentosum (mean $\pm \mathrm{SD}, n=5$ ) along a 5-week growth period under white light (WL), red light (RL), and blue light (BL). Different letters indicate, for each week, significant differences between light treatments at $p<0.05$ under BL, whereas differences between RL and WL were only statistically significant $(p<0.01)$ for weeks 1 and 2 .

Maximum quantum yield $\left(F_{\mathrm{v}} / F_{\mathrm{m}}\right)$ values of $C$. tomentosum at week 5 under $\mathrm{WL}, \mathrm{BL}$, and RL treatments were similar ( $0.69 \pm 0.03,0.68 \pm 0.04$, and $0.71 \pm 0.02$, respectively). Light curves were also similar for light spectral treatments, with rETR increasing with irradiance and saturating at light intensities slightly higher than the growth irradiance of $120 \mu \mathrm{mol}$ photons $\mathrm{m}^{-2} \mathrm{~s}^{-1}$ (Fig. 7). Relative electron transport rate slightly decreased under higher irradiances (397 and $604 \mu \mathrm{mol}$ photons $\mathrm{m}^{-2} \mathrm{~s}^{-1}$ ) for WL grown alga, indicating photoinhibition. However, no significant differences were observed between WL, BL, and RL treatments for SSLC parameters $\alpha(0.69 \pm 0.05,0.78 \pm 0.09$ and $0.75 \pm 0.05$, respectively) and $\mathrm{rETR}_{\max }(33.3 \pm 3.6,38.2 \pm 3.7$ and $35.9 \pm 4.3$, respectively).

No significant differences were observed between light spectral treatments in the concentrations of the pigments $t$ Neo, Viola, and Chla. However, the average concentrations for the majority of identified pigments were higher under BL (Fig. 8). Concentrations of $c$-Neo, Siph-do, and Chl $b$ were significantly higher $(p<0.05)$ under BL than RL and WL. Concentrations of Siph and $\beta \varepsilon$-car were significantly higher under BL than RL.

\section{Discussion}

Seaweed growth, reproduction, and chemical composition are affected by the interaction of temperature, nutrients, and light (Lüning 1990; Lobban and Harrison 1994). Thus, understanding the combined effects of these parameters is crucial for any long-term commercial algae farm operation (Pereira et al.

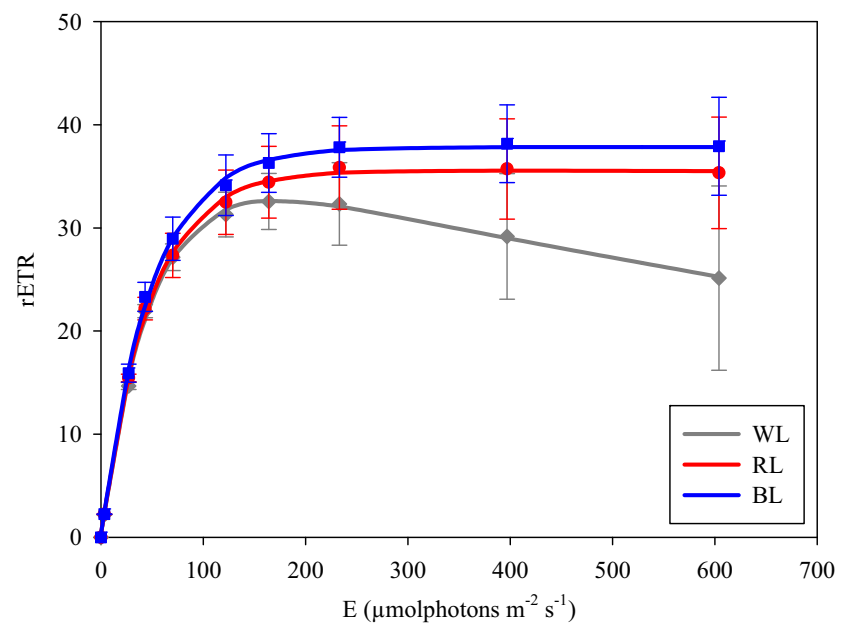

Fig. 7 Steady state light-response curves of relative electron transport rate (rETR) vs. photon irradiance (E) in Codium tomentosum (mean \pm $\mathrm{SD}, n=5$ ) after 5-weeks under white light (WL), red light (RL), and blue light (BL). Lines represent curve fits according to the model of Platt et al. (1980) 


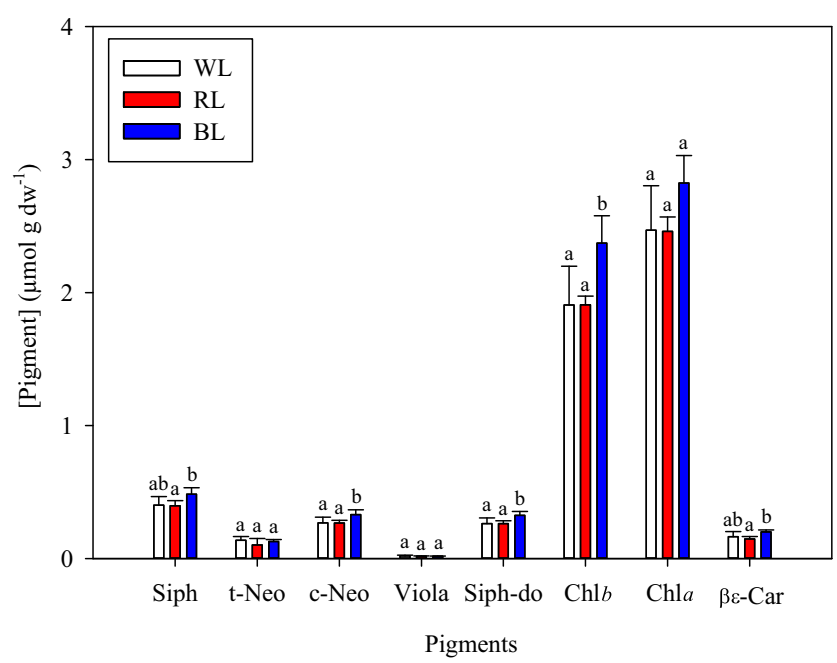

Fig. 8 Pigment content in Codium tomentosum (mean $\pm \mathrm{SD}, n=5$ ) at week 5 under white light (WL), red light (RL), and blue light (BL). Different letters indicate significant differences between light treatments at $p<0.05$

2004; Abreu et al. 2011). Relative growth rates of the macroalga $C$. tomentosum under culture conditions were ca. $2 \times$ higher under long-day photoperiod (LD, $16 \mathrm{~h}$ light: $8 \mathrm{~h}$ dark) compared with short-day photoperiod (SD, $8 \mathrm{~h}$ light:16 h dark). Main photosynthetic parameters determined by PAM fluorometry were identical between LD and SD, indicating that higher productivity under LD conditions were likely due to the longer period of light exposure and not to changes in photosynthetic efficiency.

According to Hanisak (1979), seasonal growth of C. fragile ssp. tomentosoides is primarily determined by the interaction of temperature and irradiance. In culture experiments, higher growth rates of this Codium species were observed at 18 and $24{ }^{\circ} \mathrm{C}$ under long-day photoperiods (Hanisak 1979). However, a decrease in growth rate was observed for the combination of higher temperature and irradiance $\left(24{ }^{\circ} \mathrm{C}\right.$, $150 \mu \mathrm{mol}$ photons $\mathrm{m}^{-2} \mathrm{~s}^{-1}$ ). Codium fragile culture experiments were conducted by Hwang et al. (2008) using seed fibers and cultivation ropes. Higher growth rates for premain cultivation stage of $C$. fragile were obtained at $2 \mathrm{~m}$ depth, corresponding to a mean irradiance of ca. $250 \mu \mathrm{mol}$ photons $\mathrm{m}^{-2} \mathrm{~s}^{-1}$ (Hwang et al. 2008). Nanba et al. (2005) observed that the growth of the spongy thalli of $C$. fragile greatly accelerated under the combination of higher irradiance and water flow $\left(200 \mu \mathrm{mol}\right.$ photons $\mathrm{m}^{-2} \mathrm{~s}^{-1}$ and $10 \mathrm{~cm} \mathrm{~s}^{-1}$, respectively). In our study, despite ca. $2 \times$ fold higher irradiance in the photoperiod experiment $(230 \mu \mathrm{mol}$ photons $\mathrm{m}^{-2} \mathrm{~s}^{-1}$ ), compared with the light spectra experiment $\left(120 \mu \mathrm{mol} \mathrm{m} \mathrm{m}^{-2} \mathrm{~s}^{-1}\right)$, average relative growth rate under WL was only $20 \%$ higher (39.2 and $31.5 \%$ week $^{-1}$, respectively). Hence, we conclude that optimum light intensity for C. tomentosum growth is within the $120-230 \mu$ mol photons $\mathrm{m}^{-2} \mathrm{~s}^{-1}$ range.
In most cases, studies on the effect of light on the growth of macroalgae involve manipulation of the integrated photosynthetically active photon irradiance, while spectral composition is commonly overlooked. However, spectral composition of available light may significantly affect macroalgal growth (Figueroa et al. 1995). Relative growth rate observed for C. tomentosum was significantly higher under red light than under blue light (36.7 and $21.8 \%$ week $^{-1}$, respectively). This was rather surprising considering that Sipho-type light-harvesting complexes of Codium have a higher absorption in the blue-green region of the light spectra (Anderson 1983; Benson and Cobb 1983). Main photosynthetic parameters determined by PAM fluorometry were identical between blue and red light, showing that spectral light acclimation did not affect the photochemical reactions of photosynthesis. However, spectral light acclimation may have significantly affected the metabolic use of energy and carbon allocation patterns. Figueroa et al. (1995) cultivated the macroalga Porphyra umbilicalis for 4 weeks in either blue or red light at the same photon flux density and found higher growth rates under red light. The authors observed that red light favored thallus expansion, cell division, and polysaccharide production, whereas blue light favored pigment and protein synthesis. Jungandreas et al. (2014) studying light acclimation processes in the microalgae Phaeodactylum tricornutum found that red to blue light shift led to a redirection of carbon into the synthesis of proteins, whereas during the blue to red light shift an accumulation of carbohydrates occurred. These differences in carbon partitioning significantly affected growth with severe inhibition in the red to blue transition (Jungandreas et al. 2014). Noteworthy was the overgrowth of green microalgae observed in blue light cultures of C. tomentosum. Competition of microalgae with C. tomentosum for available light and nutrients could also explain the reduced productivity recorded in the present study under blue light.

Photosynthetic organisms, such as macroalgae, are able to manipulate the composition of their photosynthetic apparatus, in particular their pigment composition, in order to optimize their light harvesting properties. Photoperiod affected pigment composition of $C$. tomentosum, with significantly higher concentrations of major light harvesting pigments such as Chla and Siph under long-day conditions. Spectral composition of light also affected pigment composition of $C$. tomentosum, although concentrations were similar under white and red light. On the contrary, concentrations were generally higher under blue light, particularly for Siph, $c$-Neo, Siph-do, Chlb, and $\beta \varepsilon$-car. Blue light has been shown to cause higher chlorophyll production in microalgae (Jeffrey 1980; Senge and Senger 1991). In the green microalgae Chlorella and Ankistrodesmus, blue light caused an increase in total chlorophylls that was more pronounced for Chlb (Senge and Senger 1991). 
Siphonous green algae differ from other Chlorophyta in containing light harvesting complexes with xanthophylls Siph and Siph-do, as well as a higher proportion of Chlb (Anderson 1983; Wang et al. 2013). In C. tomentosum, Siph and Siph-do pigments accounted for 54\% of the total carotenoid content. Benson \& Cobb (1981) observed that Siph and Sipho-do accounted for $60 \%$ of total carotenoids in C. fragile. In $C$. tomentosum, $\mathrm{Chl} a / b$ ratios were low $(\sim 1.3)$ reflecting the large proportion of $\mathrm{Chl} b$ in comparison with the lightharvesting complexes of plants (Anderson et al. 1988). The high proportion of Siph, Siph-do, and Chlb has been related to enhanced light harvesting in deep or turbid coastal waters with higher proportions of available green and blue-green light (Anderson 1983; Benson and Cobb 1983; Wang et al. 2013). In turbid coastal waters, high absorption and scattering of longer wavelengths by dissolved or suspended particles make the ability to exploit the spectral region of blue-green light an ecological advantage (Kirk 2011). Our results suggest, however, that the evolutionary pressures on C. tomentosum that led to an increased ability to explore the blue-green region of the spectrum did not lead to a downregulation of the capability to use the spectral red region.

Photosynthesis assessment using Imaging-PAM fluorometry, which allows capturing two-dimensional images of $\mathrm{Chl}$ fluorescence parameters, revealed high spatial heterogeneity within the macroalgal thallus. Consistently higher $F_{o}$ values and lower photosynthetic yields were observed at the tips of C. tomentosum thalli. This indicates a higher chloroplast abundance in these regions (higher $F_{o}$ ) that causes a canopy effect that may limit light absorption by chloroplasts in the basal portions of the algal thallus. Giovagnetti et al. (2018) reported that the siphonous green macroalga Bryopsis corticulans can cope with excess light energy by activating sustained protective nonphotochemical quenching in algal surface filaments. While this undermined photochemistry in surface filaments, it allowed efficient photosynthetic rates deeper in the algal structure (Giovagnetti et al. 2018).

Codium and other macroalgae within the Bryopsidales lack the xanthophyll cycle (Cruz et al. 2015; Christa et al. 2017), the most ubiquitous photoprotection mechanism present in most algae and higher plants. In this cycle, Viola is converted sequentially to antheraxanthin and zeaxanthin under high irradiance, with the latter pigment playing a crucial role as energy dissipator (Goss and Lepetit 2015). In C. tomentosum, Viola represented only $1.4 \%$ of carotenoid abundance and zeaxanthin was not detected. This could be a major drawback for an intertidal and shallow subtidal macroalgae exposed to extreme light fluctuations associated with the tidal cycle. An alternative xanthophyll cycle has been observed in higher plants involving the conversion of lutein-5,6-epoxide to lutein under high irradiance (Bungard et al. 1999; Jahns and Holzwarth 2012). However, these pigments were absent in $C$. tomentosum (Table 1). The accumulation of the pigment trans-neoxanthin has been observed in $C$. intricatum and $C$. tomentosum acclimated to high irradiance (Uragami et al. 2014; Cartaxana et al. 2018), but a photoprotective role for trans-neoxanthin is yet to be established. Photoprotection in Bryopsidales is most likely provided by an array of different mechanisms that may include uncharacterized nonphotochemical quenching mechanisms, efficient D1 protein turnover and reactive oxygen species scavenging, and chloroplast streaming (Franklin and Larkum 1997; Christa et al. 2017; Giovagnetti et al. 2018).

Understanding the appropriate light requirements of C. tomentosum will assist and help to expand commercial cultivation of this macroalga. In addition, optimized cultivation conditions under IMTA systems will lower the costs associated to the treatment of excess of nutrients in the fish farm effluents to fulfill environmental regulations and enhance aquaculture revenues. We propose long-day photoperiod (LD, $16 \mathrm{~h}$ light: $8 \mathrm{~h}$ of dark) and light sources with preferential emission at the red region of the light spectra as optimal for growing $C$. tomentosum at early development stages. These conditions can reduce the time required for the initial growth phase and anticipate the transfer to grow-out systems. Increasing $C$. tomentosum productivity will help satisfying the current high demand by the market for sustainably cultured biomass of this macroalga.

Funding This study received support from $R \& D$ project CtLight (PTDC/BIA-FBT/30979/2017) funded by FEDER, through COMPETE2020 - Programa Operacional Competitividade e Internacionalização (POCI), and by national funds (OE), through FCT/ MCTES. FCT/MCTES also provided the financial support to CESAM (UIDP/50017/2020 + UIDB/50017/2020). S.C. and P.C. were funded by FCT in the frame of IF/00899/2014 and CEECIND/01434/2018, respectively.

\section{Compliance with ethical standards}

Conflict of interest The authors declare that they have no competing interests.

Open Access This article is licensed under a Creative Commons Attribution 4.0 International License, which permits use, sharing, adaptation, distribution and reproduction in any medium or format, as long as you give appropriate credit to the original author(s) and the source, provide a link to the Creative Commons licence, and indicate if changes were made. The images or other third party material in this article are included in the article's Creative Commons licence, unless indicated otherwise in a credit line to the material. If material is not included in the article's Creative Commons licence and your intended use is not permitted by statutory regulation or exceeds the permitted use, you will need to obtain permission directly from the copyright holder. To view a copy of this licence, visit http://creativecommons.org/licenses/by/4.0/.

\section{References}

Abreu MH, Pereira R, Sousa-Pinto I, Yarish C (2011) Ecophysiological studies of the non-indigenous species Gracilaria vermiculophylla 
(Rhodophyta) and its abundance patterns in Ria de Aveiro lagoon, Portugal. Eur J Phycol 46:453-464

Abreu MH, Pereira R, Sassi J-F (2014) Marine algae and the global food industry. In: Pereira L, Neto JM (eds) Marine algae - biodiversity, taxonomy, environmental assessment, and biotechnology. CRC Press, Boca Raton, pp 300-319

Akimoto S, Tomo T, Naitoh Y, Otomo A, Murakami A, Mimuro M (2007) Identification of a new excited state responsible for the in vivo unique absorption band of siphonaxanthin in the green alga Codium fragile. J Phys Chem B 111:9179-9181

Anderson JM (1983) Chlorophyll-protein complexes of a Codium species, including a light-harvesting siphonaxanthin-chlorophylla a/bprotein complex, an evolutionary relic of some Chlorophyta. Biochim Biophys Acta 724:370-380

Anderson JM, Chow WS, Goodchild DJ (1988) Thylakoid membrane organisation in sun/shade acclimation. Aust J Plant Physiol 15:1126

Benson EE, Cobb AH (1983) Pigment/protein complexes of the intertidal alga Codium fragile (Suringar) Hariot. New Phytol 95:581-594

Benson EE, Cobb AH (1981) The separation, identification and quantitative determination of photopigments from the siphonaceous marine algaCodium fragile. New Phytol 88:627-632

Bungard RA, Ruban AV, Hibberd JM, Press MC, Horton P, Scholes JD (1999) Unusual carotenoid composition and a new type of xanthophyll cycle in plants. Proc Nat Acad Sci U S A 96:1135-1139

Cartaxana P, Morelli L, Quintaneiro C, Calado G, Calado R, Cruz S (2018) Kleptoplast photoacclimation state modulates the photobehaviour of the solar-powered sea slug Elysia viridis. J Exp Biol 221:jeb180463

Christa G, Cruz S, Jahns P, de Vries J, Cartaxana P, Esteves AC, Serôdio J, Gould SB (2017) Photoprotection in a monophyletic branch of chlorophyte algae is independent of energy-dependent quenching (qE). New Phytol 214:1132-1144

Cruz S, Cartaxana P, Newcomer R, Dionísio G, Calado R, Serôdio J, Pelletreau KN, Rumpho ME (2015) Photoprotection in sequestered plastids of sea slugs and respective algal sources. Sci Rep 5:7904

Costa E, Melo T, Moreira ASP, Alves E, Domingues P, Calado R, Abreu MH, Domingues MR (2015) Decoding bioactive polar lipid profile of the macroalgae Codium tomentosum from a sustainable IMTA system using a lipidomic approach. Algal Res 12:388-397

Figueroa FL, Aguilera J, Niell X (1995) Red and blue light regulation of growth and photosynthetic metabolism in Porphyra umbilicalis (Bangiales, Rhodophyta). Eur J Phycol 30:11-18

Franklin LA, Larkum AWD (1997) Multiple strategies for a high light existence in a tropical marine macroalga. Photosynth Res 53:149159

Ganesan P, Matsubara K, Ohkubo T, Tanaka Y, Nodaa K, Sugawaraa T, Hirata T (2010) Anti-angiogenic effect of siphonaxanthin from green alga, Codium fragile. Phytomedicine 17:1140-1144

Ganesan P, Noda K, Manabe Y, Ohkubo T, Tanaka Y, Maoka T, Sugawaraa T, Hirata T (2011) Siphonaxanthin, a marine carotenoid from green algae, effectively induces apoptosis in human leukemia (HL-60) cells. Biochim Biophys Acta 1810:497-503

Giovagnetti V, Han G, Ware MA, Ungerer P, Qin X, Wang W-D, Kuang T, Shen J-R, Ruban AV (2018) A siphonous morphology affects light-harvesting modulation in the intertidal green macroalga Bryopsis corticulans (Ulvophyceae). Planta 247:1293-1306

Genty B, Briantais J-M, Baker NR (1989) The relationship between the quantum yield of photosynthetic electron transport and quenching of chlorophyll fluorescence. Biochim Biophys Acta 990:87-92

Granada L, Sousa N, Lopes S, Lemos MF (2016) Is integrated multitrophic aquaculture the solution to the sectors' major challenges? - a review. Rev Aquac 8:283-300

Goss R, Lepetit B (2015) Biodiversity of NPQ. J Plant Physiol 172:13-32
Hanisak MD (1979) Growth patterns of Codium fragile ssp. tomentosoides in response to temperature, irradiance, salinity, and nitrogen source. Mar Biol 50:319-332

Hwang EK, Baek JM, Parket CS (2008) Cultivation of the green alga, Codium fragile (Suringar) Hariot, by artificial seed production in Korea. J Appl Phycol 20:469-475

Jahns P, Holzwarth AR (2012) The role of the xanthophyll cycle and of lutein in photoprotection of photosystem II. Biochim Biophys Acta Bioenerg 1817:182-193

Jeffrey S (1980) Algal pigment systems. In: Falkowski PG (ed) Primary productivity in the sea. Springer, Boston, pp 33-58

Jungandreas A, Costa BS, Jakob T, von Bergen M, Baumann S, Wilhelm C (2014) The acclimation of Phaeodactylum tricornutum to blue and red light does not influence the photosynthetic light reaction but strongly disturbs the carbon allocation pattern. PLoS One 9: e99727

Kraay GW, Zapata M, Veldhuis MJW (1992) Separation of chlorophylls $\mathrm{c}_{1}, \mathrm{c}_{2}$ and $\mathrm{c}_{3}$ of marine phytoplankton by reversed-phase-C18-highperformance liquid chromatography. J Phycol 28:708-712

Kirk JTO (2011) Light and photosynthesis in aquatic ecosystems. Cambridge University Press, Cambridge

Lobban CS, Harrison PJ (1994) Seaweed ecology and physiology. Cambridge University Press, Cambridge

Lüning K (1990) Seaweeds - their environment, biogeography, and ecophysiology. John Wiley \& Sons, New York

Matsubara K, Matsuura Y, Hori K, Miyazawa K (2000) An anticoagulant proteoglycan from the marine green alga, Codium pugniformis. J Appl Phycol 12:9-14

Mendes CR, Cartaxana P, Brotas V (2007) HPLC determination of phytoplankton and microphytobenthos pigments: comparing resolution and sensitivity of a C18 and a C8 method. Limnol Oceanogr Methods 5:363-370

Murchie EH, Lawson T (2013) Chlorophyll fluorescence analysis: a guide to good practice and understanding some new applications. J Exp Bot 64:3983-3998

Nanba N, Kado R, Ogawa H, Nakagawa T, Sugiura Y (2005) Effects of irradiance and water flow on formation and growth of spongy and filamentous thalli of Codium fragile. Aquat Bot 81:315-325

Ohta Y, Lee J-B, Hayashi K, Hayashi T (2009) Isolation of sulfated galactan from Codium fragile and its antiviral effect. Biol Pharm Bull 32:892-898

Pereira R, Sousa-Pinto I, Yarish C (2004) Field and culture studies of the life history of Porphyra dioica (Bangiales, Rhodophyta) from Portugal. Phycologia 43:756-767

Pereira L (2018) Seaweeds as source of bioactive substances and skin care therapy - Cosmeceuticals, algotheraphy, and thalassotherapy. Cosmetics 5:68

Pérez-Lloréns J, Hernández I, Vergara J (2018) Those curious and delicious seaweeds. A fascinating voyage from biology to gastronomy. UCA Press, Cadiz

Pillay TVR (2004) Aquaculture and the environment. Blackwell Publishing, Oxford

Platt T, Gallegos CL, Harrison WG (1980) Photoinhibition of photosynthesis in natural assemblages of marine phytoplankton. J Mar Res 38:687-701

Radulovich R, Umanzor S, Cabrera R, Mata R (2015) Tropical seaweeds for human food, their cultivation and its effect on biodiversity enrichment. Aquaculture 436:40-46

Rey F, Cartaxana P, Melo T, Calado R, Pereira R, Abreu H, Domingues P, Cruz S, Domingues MR (2020) Domesticated populations of Codium tomentosum display lipid extracts with lower seasonal shifts than conspecifics from the wild - relevance for biotechnological applications of this green seaweed. Mar Drugs 18:188

Samaraweera AM, Vidanarachchi JK, Kurukulasuriya MS (2011) Industrial applications of macroalgae. In: Kim S-K (ed) Handbook 
of marine macroalgae: biotechnology and applied phycology. John Wiley \& Sons, Chichester, pp 500-521

Santos SAO, Vilela C, Freire CSR, Abreu MH, Rocha SM, Silvestre AJD (2015) Chlorophyta and Rhodophyta macroalgae: a source of health promoting phytochemicals. Food Chem 183:122-128

Senge M, Senger H (1991) Adaptation of the photosynthetic apparatus of Chlorella and Ankistrodesmus to blue and red light. Bot Acta 104: 139-143

Troell M, Halling C, Neori A, Chopin T, Buschmann AH, Kautsky N, Yarish C (2003) Integrated mariculture: asking the right questions. Aquaculture 226:69-80

Uragami C, Galzerano D, Gall A, Shigematsu Y, Meisterhans M, Oka N, Iha M, Fujii R, Robert B, Hashimoto H (2014) Light-dependent conformational change of neoxanthin in a siphonous green alga, Codium intricatum, revealed by Raman spectroscopy. Photosynth Res 121:69-77
Wang H-MD, Chen C-C, Huynh P, Chang J-S (2015) Exploring the potential of using algae in cosmetics. Bioresour Technol 184:355362

Wang L, Wang X, Wu H, Liu R (2014) Overview on biological activities and molecular characteristics of sulfated polysaccharides from marine green algae in recent years. Mar Drugs 12:4984-5020

Wang W, Qin X, Sang M, Chen D, Wang K, Lin R, Lu C, Shen JR, Kuang T (2013) Spectral and functional studies on siphonaxanthintype light-harvesting complex of photosystem II from Bryopsis corticulans. Photosynth Res 117:267-279

Yang MH, Blunden G, Huang FL, Fletcher RL (1997) Growth of a dissociated, filamentous stage of Codium species in laboratory culture. J Appl Phycol 9:1-3

Publisher's note Springer Nature remains neutral with regard to jurisdictional claims in published maps and institutional affiliations. 